\title{
Penerapan Tema The Scenic of Archipelago pada Perancangan Interior Museum Nasional Indonesia
}

\author{
Orlando Gamal ${ }^{1}$, Noeratri Andanwerti ${ }^{2}$, Naniek Widayati ${ }^{2}$ \\ Program Studi Desain Interior, Universitas Tarumanagara \\ gamal.orlando@gmail.com, noeratria@fsrd.untar.ac.id, naniekw@ft.untar.ac.id
}

\begin{abstract}
Abstrak-Pesatnya perkembangan zaman menunjukkan museum tidak lagi hanya berperan sebagai tempat benda koleksi kuno, tetapi juga memiliki fungsi pendidikan sekaligus rekreasi. Museum menjadi tempat favorit bagi orang Eropa untuk dikunjungi. Namun, hal itu tidak terjadi di Indonesia. Pandangan masyarakat yang masih menganggap museum sebagai tempat yang kuno, gelap, kotor, berdebu, kurang interaktif ini menjadikan tingkat kunjungan masyarakat Indonesia ke museum masih sangat rendah, sehingga kurang diminati. Salah satu Museum di Indonesia yaitu Museum Nasional Indonesia masih memperlihatkan cara display yang konvensional sehingga kurang menarik bagi pengunjung yang ada. Jumlah pengunjung museum ini masih sangat sedikit yaitu hanya sekitar 10\% dari total pengunjung National Museum of Singapore. Oleh karena itu, dibutuhkan penyajian koleksi yang interaktif dan perencanaan interior akan masalah-masalah program aktivitas, ruang, serta konsep desain yang menarik agar pandangan museum yang debu dan angker dapat berubah menjadi tempat rekreasi dan edukasi yang baik serta berskala internasional. Metode yang dipakai dalam proses perancangan museum ini adalah studi literatur, observasi lapangan, studi banding, space planning, konsep desain, studi alternatif desain dan keputusan desain berupa gambar presentasi dan gambar kerja. Hasil dari proses perancangan adalah mengangkat tema "The Scenic of Archipelago" yang dinilai dapat menggambarkan dan mengangkat budaya Indonesia ke dalam interior Museum Nasional Indonesia untuk Gedung B dan C.
\end{abstract}

Kata kunci: museum, display, interior, interaktif, archipelago

\section{PENDAHULUAN}

Pesatnya perkembangan museum dari waktu ke waktu menunjukkan bahwa museum telah menjadi sebuah institusi publik penting yang tidak hanya berfungsi sebagai tempat penyimpanan koleksi benda-benda kuno, tetapi juga memiliki fungsi penting lainnya yaitu pendidikan, dimana masyarakat dapat menambah wawasan ilmu pengetahuan, informasi, serta berinteraksi secara langsung dengan objek-objek yang ada di dalam museum.

Museum menjadi suatu tempat tujuan wisata yang populer bagi masyarakat dan beragam kelompok usia, terutama di luar negeri, dimana mereka banyak menghabiskan waktu senggang bersama keluarga, berekreasi sekaligus relaksasi. Namun, hal itu tidak terjadi di Indonesia. Pandangan masyarakat yang masih menganggap museum sebagai tempat yang kuno, gelap, kotor, berdebu, kurang interaktif ini menjadikan tingkat kunjungan masyarakat Indonesia ke museum masih sangat rendah, sehingga kurang diminati.

Sesuai dengan perubahan karakter masyarakat di dunia maupun di Indonesia, karakter pengunjung museum dewasa ini juga mengalami perubahan. Walaupun datang dari berbagai kelompok usia, tingkat pendidikan, dan struktur sosial, mereka menginginkan hal yang sama yaitu melihat sebuah pameran tempat mereka dapat berperan serta, tidak sekadar menjadi penonton pasif, namun juga terlibat di dalamnya. Pengunjung bukanlah lagi menjadi pelengkap pameran, melainkan 
menjadi faktor utama dan alasan dari pameran tersebut diadakan. Tanpa adanya konsep pameran yang menarik, pencahayaan yang redup dan kurang di mana-mana, serta alur sirkulasi yang membingungkan membuat museum-museum di Indonesia menjadi tempat yang angker, gelap, kotor, tidak menarik dan kurang diminati. Inilah permasalahan utama bagi museum-museum di Indonesia salah satunya yaitu Museum Nasional Indonesia.

Tujuan dari perancangan interior ini adalah untuk menjawab permasalahan-permasalahan aktivitas ruang di area pameran, lobi, cafetaria, souvenir shop di dalam Gedung B dan $C$, dan kanopi urban sebagai penghubung Gedung A dan B-C sehingga sesuai dengan visi misi Museum Nasional sebagai museum bertaraf internasional.

\section{METODE}

Metode perancangan yang digunakan dalam proses perancangan Museum Nasional Indonesia adalah sebagai berikut :

\section{a. Tahap Programming}

1) Studi Literatur

Pengumpulan data dengan cara mengumpulkan literatur, jurnal, paper, browsing dari internet, yang ada kaitannya dengan perancangan museum.

2) Observasi
Pengumpulan data dengan cara survei langsung ke lapangan, mengumpulkan data kondisi existing dari museum, wawancara dengan pihak pengelola museum.

3) Studi Banding

Melakukan survei ke beberapa museum lain dan membandingkannya dengan museum yang akan dirancang.

b. Tahap Analisis Data

Melakukan studi zoning, grouping, branding/image sesuai dengan pedoman literatur dan masalah eksisting di museum.

c. Tahap Penyusunan Konsep

Penerapan konsep dilakukan setelah menganalisis masalah image dari museum dan konteks budaya untuk mengangkat budaya Indonesia ke kancah internasional.

d. Tahap Keputusan Desain

Keputusan desain merupakan implementasi konsep desain terhadap interior museum. Tahap ini akan memberikan hasil perancangan desain berupa gambar kerja dan gambar presentasi.

Metode pengumpulan gambar kerja meliputi : Site plan, layout plan, furniture plan, floor plan, ceiling plan, electrical plan, potongan \& detail, tampak. Metode pengumpulan 
gambar presentasi meliputi: Layout plan, tampak, perspektif interior, aksonometri, skema material dan warna, skema furniture.

\section{HASIL DAN PEMBAHASAN}

A. Analisis Citra/Image

Berdasarkan beberapa variabel yaitu status Lembaga, visi/misi, logo, pengguna, fungsi, benda koleksi, dan bangunan eksisting, dapat disimpulkan image yang diharapkan dari Museum Nasional Indonesia adalah International Indonesia Heritage.

B. Analisis Potensi Lingkungan/Tapak

Museum Nasional Indonesia berlokasi di Jalan Medan Merdeka Barat No.12, Jakarta Pusat. Kawasan ini terletak di pusat kota yang cukup ramai dan strategis karena dekat dengan pusat wisata lainnya yaitu Monumen Nasional, akses transportasi publik seperti busway juga mudah karena letak halte langsung berseberangan dengan museum.

- Arah Utara : Mahkamah Konstitusi, Kementrian Komunikasi dan Informatika

- Arah Selatan : Kementerian Pertahanan Republik Indonesia

- Arah Barat : Universitas Brawijaya Jakarta, SMK Jakarta Pusat 1

- Arah Timur : Monumen Nasional

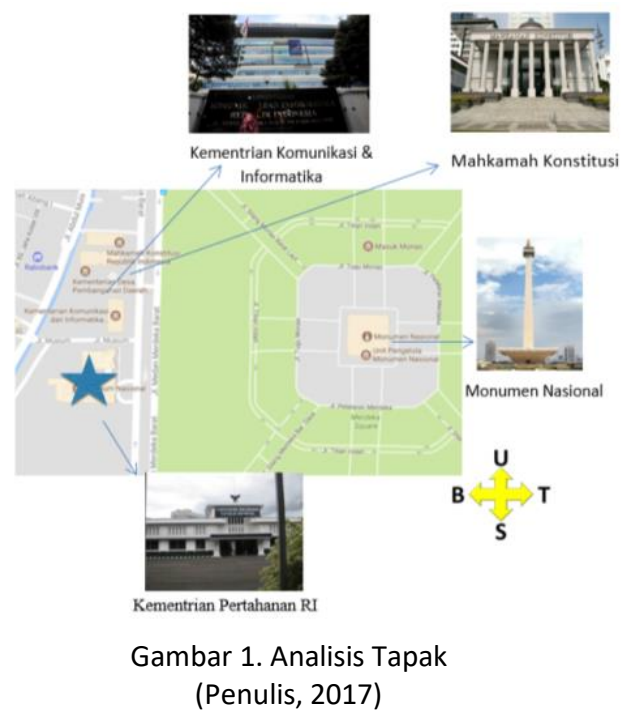

C. Analisis Statistik Pengunjung

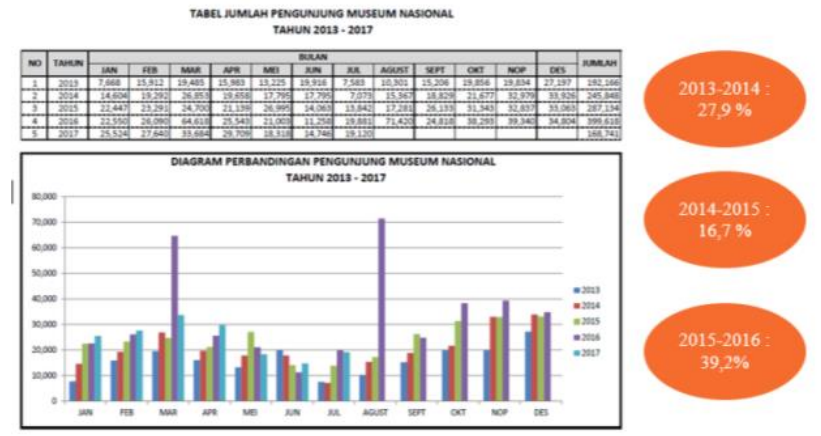

Gambar 2. Statistik Pengunjung (Arsip Museum Nasional, 2017)

- Pengunjung terbanyak : anak - anak (SD) \& Keluarga

- Terdapat pengunjung mancanegara (Korea, Jepang, Inggris, Belanda, Perancis, Jerman, dll)

D. Analisis Bangunan Baru

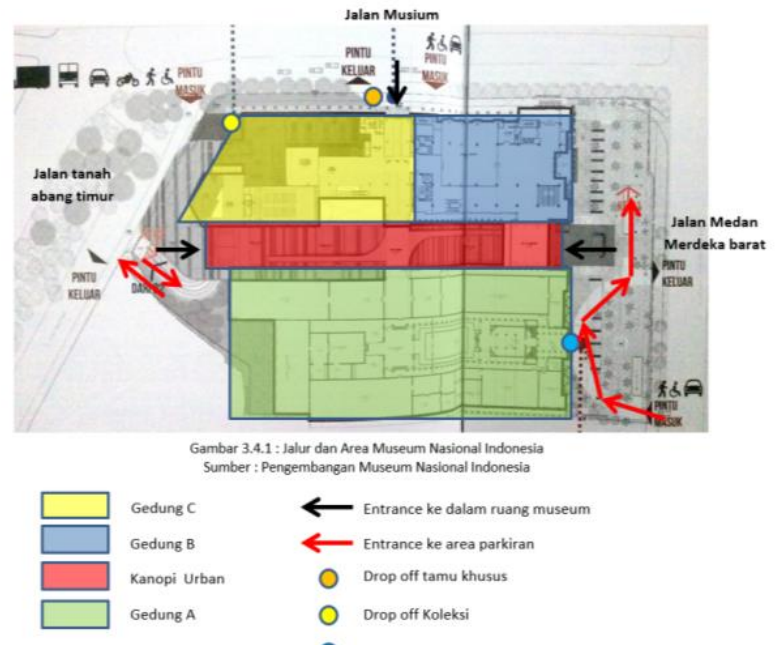

Gambar 3. Analisis Bangunan Baru (Penulis, 2017) 
- Ada perubahan jalur entrance ke dalam ruangan museum : semuanya melewati area Kanopi Urban (warna merah) dan dari arah Jalan Musium

- Terdapat 3 pintu masuk ke dalam area museum : dari Jalan Medan Merdeka Barat, Jalan Musium, dan Jalan Tanah Abang Timur

\section{E. Analisis Perilaku Pengunjung Museum}

Tabel 1 : Tabel Analisis Perilaku Pengunjung Sumber: Diolah dari berbagai sumber, 2017

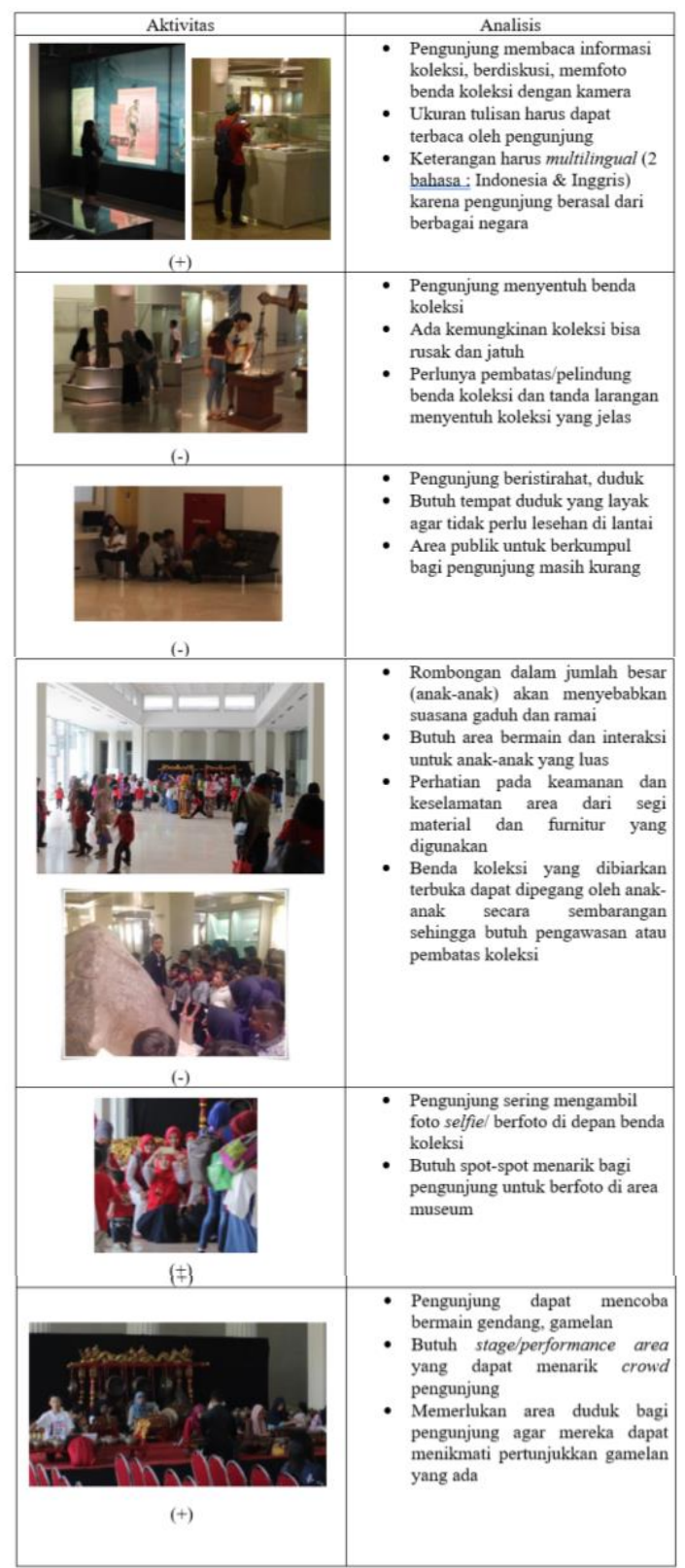

F. Analisis Masalah Ruang Eksisting

Pada bagian lobi Museum Nasional Indonesia belum tersedia meja receptionist/meja informasi sehingga cukup membingungkan bagi pengunjung baru untuk bertanya mengenai museum. Juga belum tersedia area tempat duduk bagi pengunjung untuk sekedar beristirahat. First impression untuk bagian lobi museum belum menarik dan kurang fungsional, serta hanya mengandalkan kondisi existing bangunan bergaya klasik saja. Desain untuk ceiling, dinding, belum terolah dengan baik. Tempat penitipan barang tidak layak karena kurang lemari penyimpanan, sehingga tas-tas yang harus dititipkan hanya diletakkan di lantai saja. Area cafetaria hanya dapat menampung 30 orang saja, desain café juga masih belum harmonis dengan suasana interior museum secara keseluruhan. Tanda petunjuk/signage masih sangat kurang, sehingga pengunjung tidak tahu arah menuju ke ruang-ruang lain, penempatan signage existing dan desainnya masih dirasa kurang tepat karena pengunjung tidak dapat mendeteksi letak signage dan ukurannya yang kecil dan tidak menarik.

Area untuk Anak (Kids Corner) masih kurang luas karena harus dapat menampung jumlah pengunjung anak-anak sekitar 50 lebih, namun kondisi existing hanya mampu efektif menampung 30 anak saja, fasilitas untuk di dalam area ini masih kurang menarik 
dan dirasa kurang terbuka bagi publik karena letaknya di basement dan kurang dari jangkauan publik. Souvenir shop yang terletak di basement masih sangat kurang dengan alasan areanya yang kecil, gelap, tidak terurus dengan baik, dan tidak mencerminkan sebagai tempat membeli souvenir museum. Area interior museum masih kurang memperhatikan untuk pengguna disabilitas mulai dari akses pintu masuk, menuju basement, dan toilet belum ada untuk disabilitas.

\section{G. Analisis Organisasi Ruang}

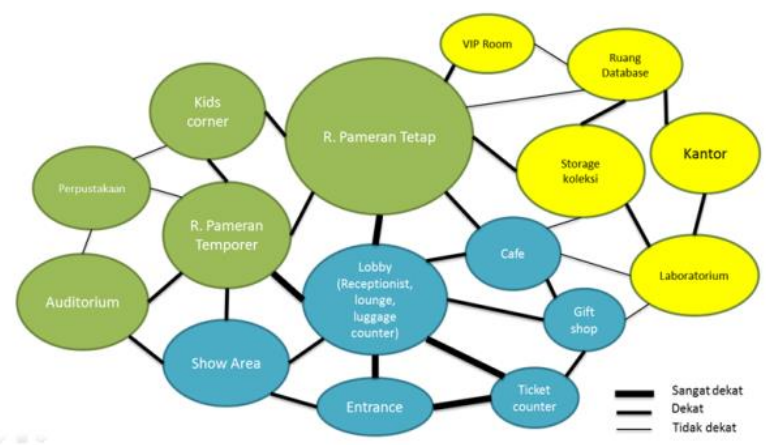

Gambar 4. Bubble Diagram Museum Nasional Indonesia (Sumber : Dokumentasi Penulis, 2017)

H. Analisis Display Koleksi
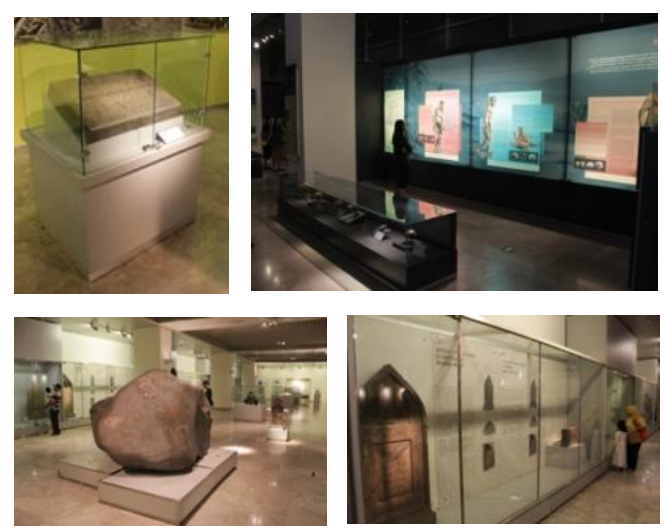

Gambar 5. Display Koleksi Museum (Sumber : Dokumentasi Penulis, 2017)
- Kurang interaktif (sentuhan teknologi)

- Monoton

- Komunikasi 1 arah

- Storyline random

- Mayoritas vitrin kaca

- Ambience ruangan sangat kurang

I. Analisis Koleksi

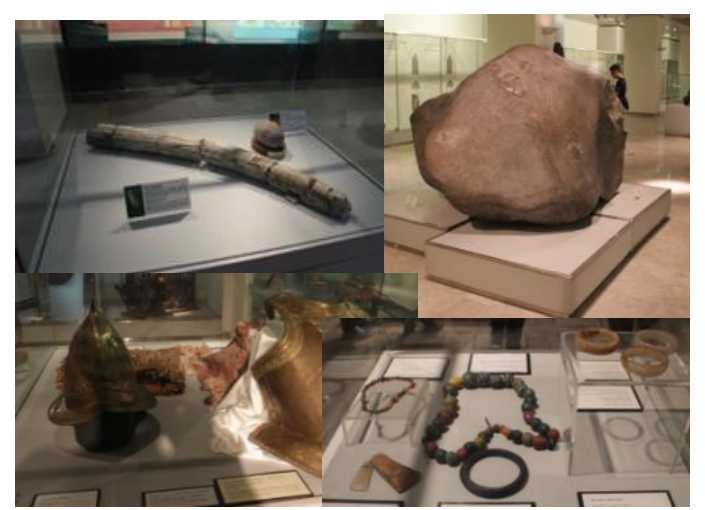

Gambar 6. Koleksi Museum Nasional Indonesia (Sumber : Dokumentasi Penulis, 2017)

- Koleksi prasasti diberikan pelindung agar tidak dapat dipegang langsung walau hanya replika

- Desain caption lebih menarik dan posisi harus dapat terlihat dalam jangkauan mata ketika berdiri

- Tanda dilarang pegang harus universal (multilingual dan logo)

- Posisi koleksi masih random, yang sejenis sebaiknya dijadikan satu area

- Koleksi berukuran besar seharusnya bisa menjadi centerpiece area 


\section{J. Konsep Citra}

Berdasarkan hasil analisis citra di Bab III, maka citra yang akan ditampilkan pada interior Museum Nasional Indonesia adalah "International Indonesian Heritage". Artinya kesan museum yang akan disampaikan adalah museum bertaraf internasional dan mampu menyajikan informasi sejarah dan peninggalan budaya Indonesia yang sangat beragam.

Suasana budaya tradisional Indonesia dapat dikemas secara kontemporer dalam penerapan elemen-elemen interior di dalam museum. Kesan dinamis, interaktif, dan edukatif juga akan ditonjolkan agar pengunjung dapat berperan lebih aktif dan berinteraksi dengan koleksi maupun fasilitas yang ada di museum.

Pandangan masyarakat akan museum sebagai tempat yang angker, berdebu, gelap, juga diubah dengan penerapan konsep yang sangat welcome dan open space serta banyak melibatkan tempat berkumpul. Hal ini menjadi langkah yang tepat untuk mengubah pandangan lama masyarakat akan museum.

\section{K. Konsep Tema}

Berdasarkan pertimbangan visi misi, benda koleksi, fungsi, dan pengunjung museum, maka tema yang dipilih adalah The Scenic of Archipelago.
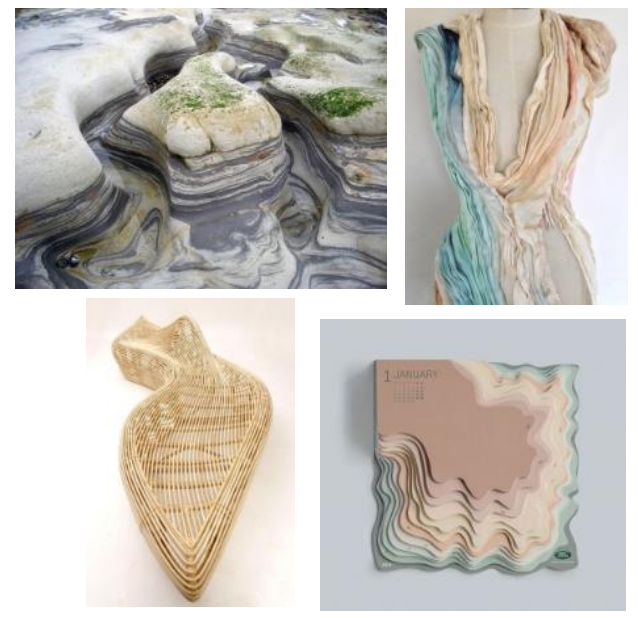

Gambar 7. Image Reference (Sumber : Pinterest, 2017)

Menampilkan view dari ragam budaya Indonesia masa lalu, masa kini, dan masa depan yang terinspirasi dari Indonesia sebagai negara kepulauan yang kaya akan sumberdaya alam yang eksotis, dengan mengambil tiga subkonsep utama yaitu oceanic islands, volcanic mountains, dan exotic floras.

\section{Konsep Suasana}

Suasana yang ingin ditampilkan dalam interior Museum Nasional Indonesia adalah :

\section{a. Open \& Light}

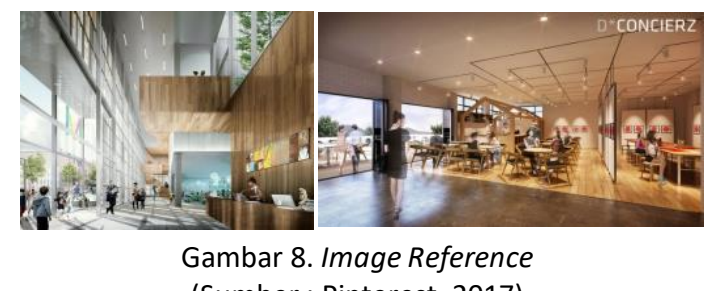

(Sumber : Pinterest, 2017)

b. Interaktif \& edukatif

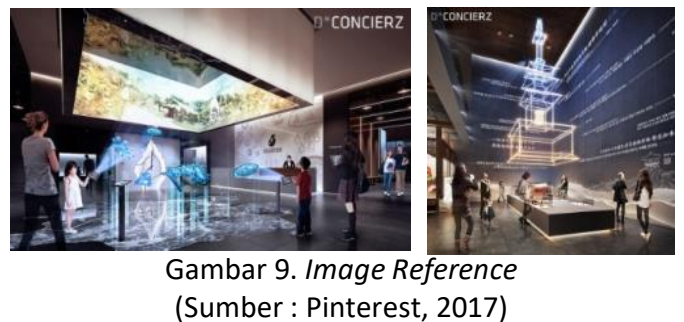




\section{c. Indonesian culture}

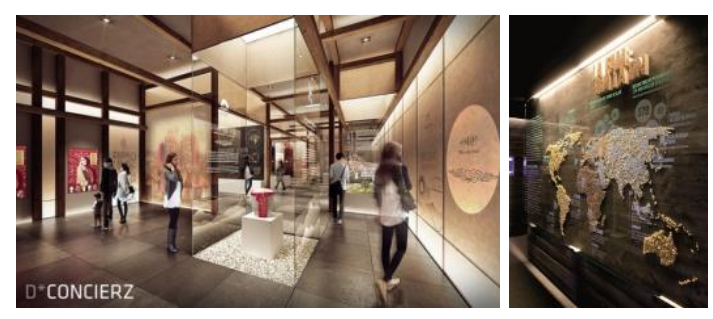

Gambar 10. Image Reference

(Sumber : Pinterest, 2017)

M. Konsep Layout
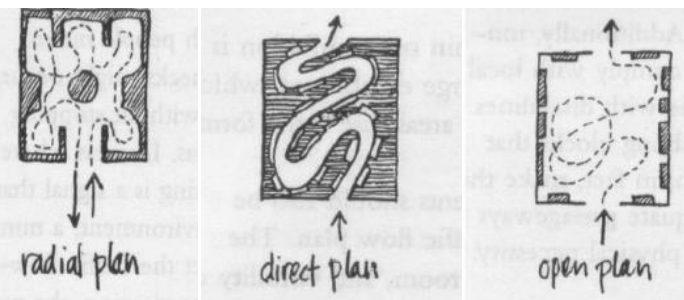

Gambar 11. Konsep Layout

(Sumber : Pinterest, 2017)

Konsep direct plan dipakai pada area pameran agar pengunjung dapat menikmati setiap koleksi museum sesuai dengan storyline yang ditetapkan dan pengunjung tidak kebingungan mencari arah dan bosan ketika melihat koleksi. Penempatan furnitur pada area pameran adalah linier dengan beberapa tempat duduk di sepanjang ruang pameran, penempatan benda koleksi diletakkan secara acak namun tetap terarah agar pengunjung dapat mengikuti alur storyline dengan jelas.

Konsep radial plan dipakai untuk area lobby dan lounge dengan receptionist/meja informasi menjadi pusat dari kegiatan utama yang berlangsung di dalam lobi. Konsep open plan dipakai juga untuk area-area terbuka seperti lobby-lounge, cafetaria, perpustakaan, kids corner, auditorium untuk memberi kesan terbuka dan luas, serta mengundang lebih banyak interaksi antara pengunjung dengan fasilitas yang ada di dalam museum.

\section{N. Konsep Dinding, Ceiling, Lantai}

Konsep dinding, ceiling, dan lantai mengambil inspirasi dari tema The Scenic of Archipelago dengan penerapan layering treatment yang terinspirasi dari bentukbentuk lengkung dari kepulauan yang ada di Indonesia, dimana kesan bentuk yang ingin disampaikan adalah dinamis dan interaktif.
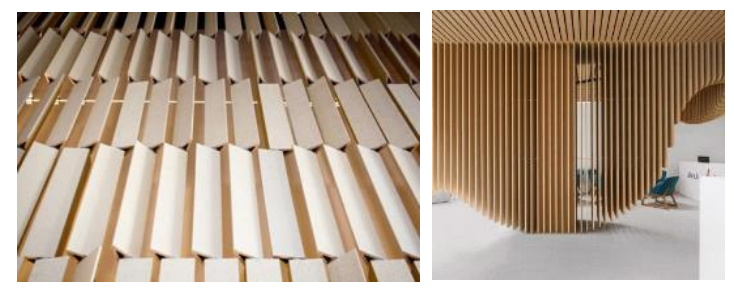

Gambar 12. Konsep dinding

(Sumber : Pinterest, 2017)

Penerapan elemen ceiling memakai wood treatment dengan garis-garis horizontal/vertikal, pada bagian center point diberikan elemen estetik seperti hanging lamp ataupun decorative elements untuk menghiasi ruangan (dapat terinspirasi dari rotan dengan penggunaan beberapa latar).

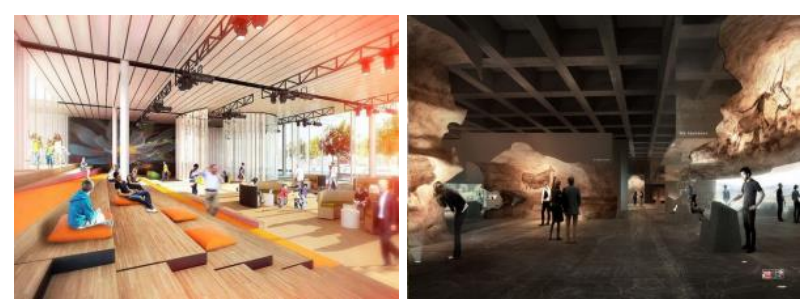

Gambar 13. Konsep ceiling (Sumber : Pinterest, 2017) 
Konsep lantai memakai penerapan bentuk-bentuk lengkung yang terinspirasi dari bentuk-bentuk kepulauan/archipelago di Indonesia, memakai material epoxy resin dengan berbagai warna dapat memberi kesan bentuk pulau dan laut yang lebih natural atau pemakaian pattern pada lantai yang terinspirasi dari bentuk batik Indonesia, memakai lantai kayu dan marmer pada beberapa area publik untuk memberi kesan grand dan mewah pada museum.

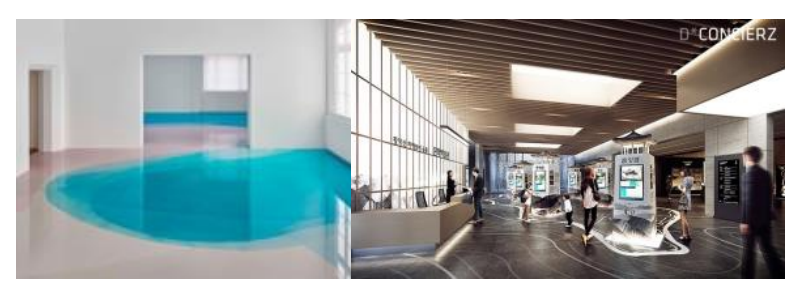

Gambar 14. Konsep lantai (Sumber : Pinterest, 2017)

\section{O. Konsep Display}

Konsep display yang dipakai untuk menunjukkan koleksi museum lebih menekankan pada konsep interaktif, sensory, dan modern. Konsep interaktif digunakan karena seiring perkembangan zaman pengunjung ingin berperan aktif dalam interaksinya dengan display yang ada sehingga digunakanlah unsur-unsur pendekatan teknologi yang dapat membantu pengunjung untuk memahami koleksi secara lebih menarik. Konsep sensory lebih menekankan kepada pengalaman pengunjung ketika melihat benda koleksi, bagaimana cara benda koleksi ditampilkan dapat membawa pengunjung seperti berada pada zaman dimana koleksi itu berada, contohnya seperti di dalam gua dengan bantuan suara-suara air dan kondisi lembab dapat melibatkan indera penglihatan, peraba, sekaligus pendengaran pengunjung di dalam ruang pameran.

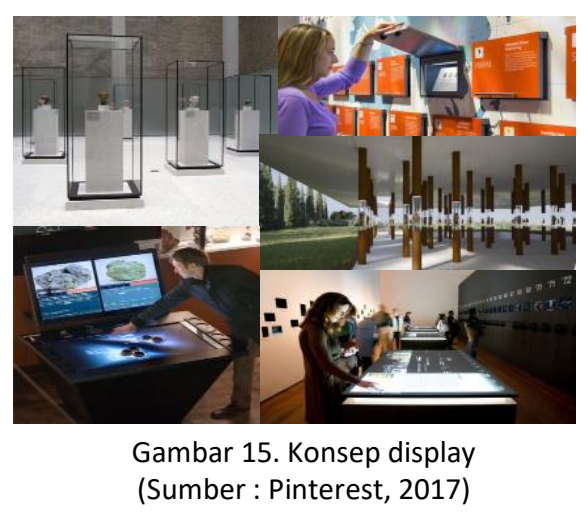

\section{SIMPULAN}

\section{A. Layout}

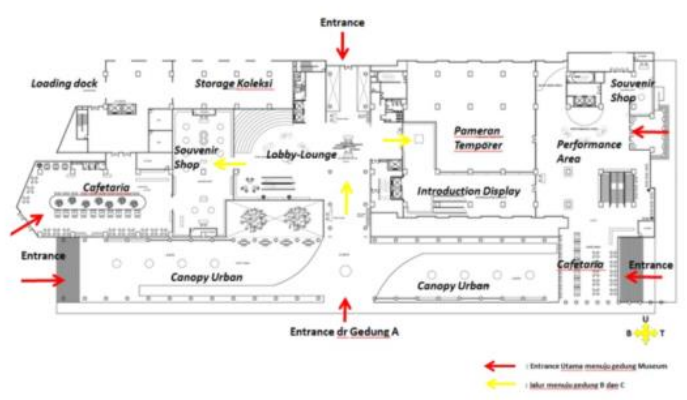

Gambar 16. Layout It. 1 Museum Nasional Indonesia (Sumber : Penulis, 2018)

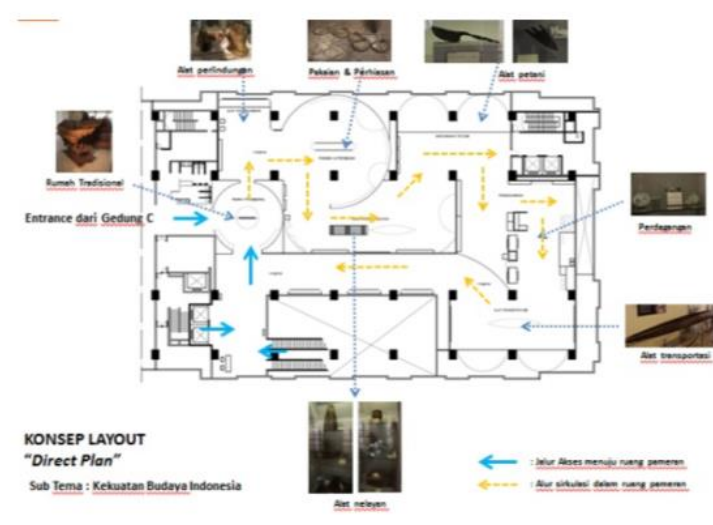

Gambar 17. Layout It. 3 Ruang pameran tetap (Sumber : Penulis, 2018) 


\section{B. Hasil Desain}

Penerapan konsep The Scenic of Archipelago pada interior Museum Nasional Indonesia bertujuan untuk mengangkat nilainilai budaya dan kekayaan alam Indonesia ke dalam bentuk ruang publik yaitu museum. Konsep ruang terbuka dan unsur-unsur alam, serta penataan cahaya yang baik pada interior museum dan kanopi urban diharapkan dapat mengubah persepsi masyarakat Indonesia akan museum yang kotor dan berdebu, menjadi museum bertaraf internasional yang kaya akan nilai sejarah dan budaya Nusantara.

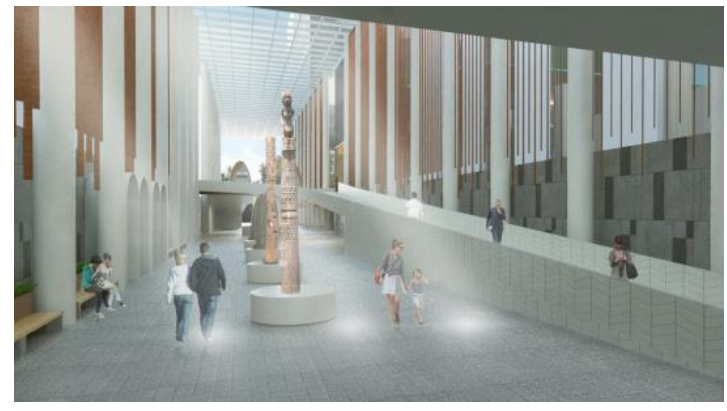

Gambar 18. Kanopi Urban view 1 (Sumber : Penulis, 2018)

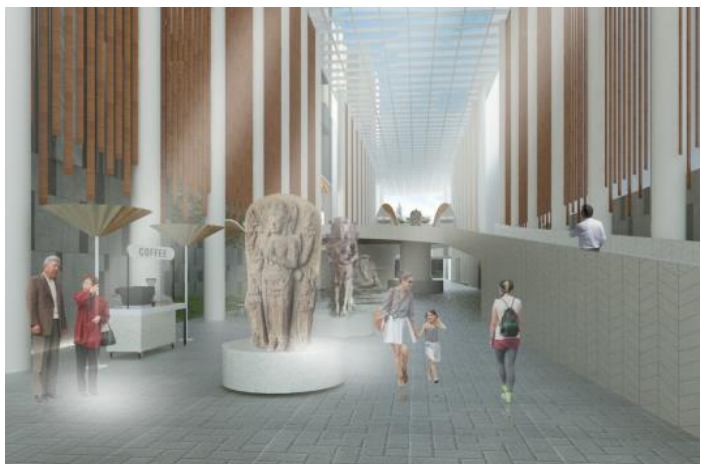

Gambar 19. Kanopi Urban view 2 (Sumber : Penulis, 2018)

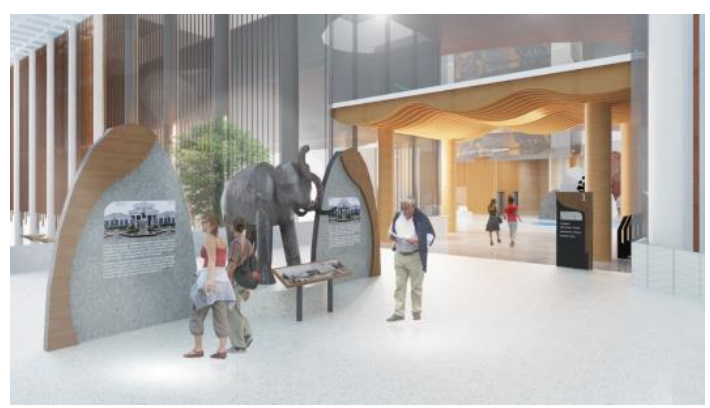

Gambar 20. Entrance gate

(Sumber : Penulis, 2018)

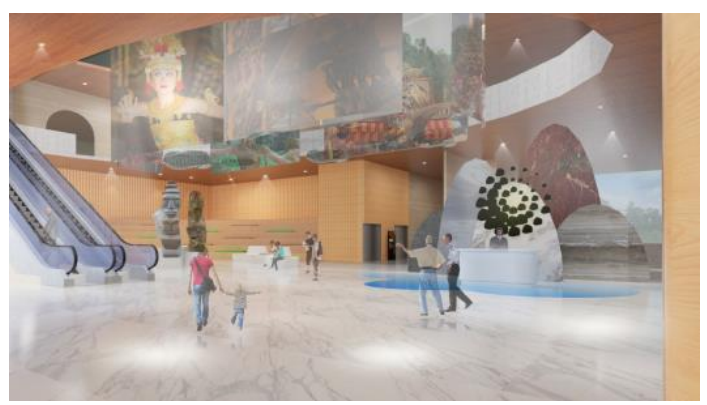

Gambar 21. Lobby

(Sumber : Penulis, 2018)

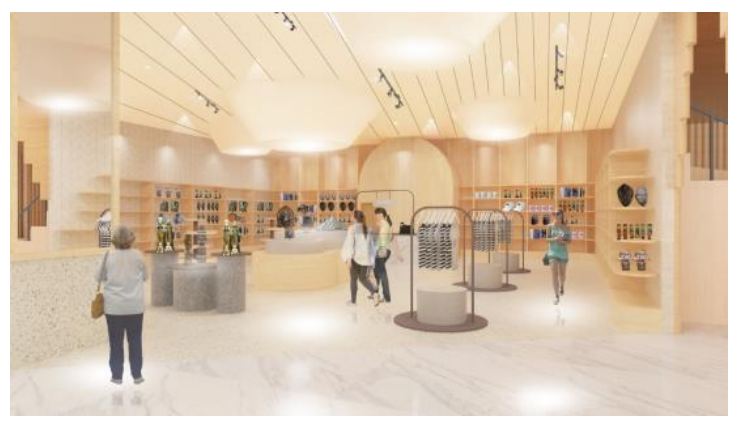

Gambar 22. Souvenir shop

(Sumber : Penulis, 2018)

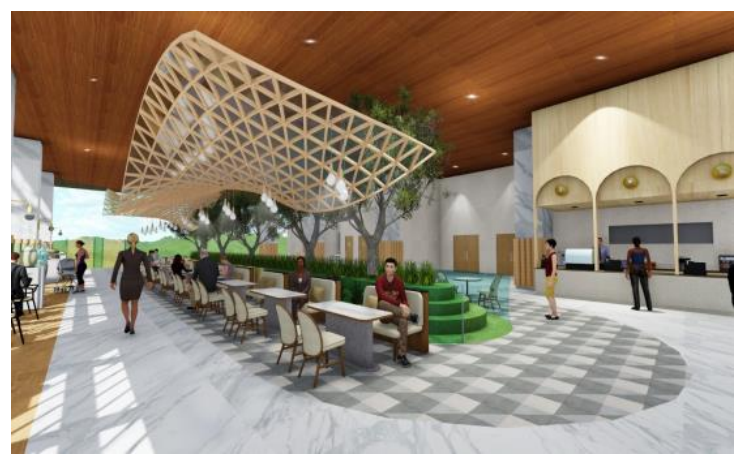

Gambar 23. Cafetaria (Sumber : Penulis, 2018) 


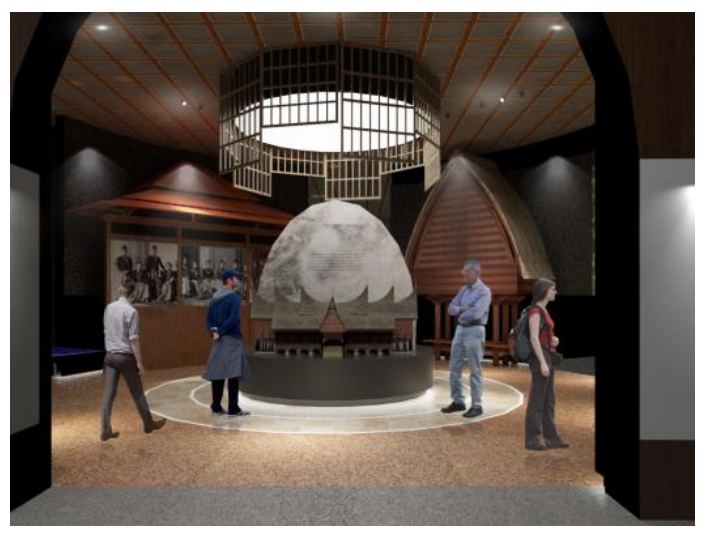

Gambar 24. Pameran Rumah Tradisional (Sumber : Penulis, 2018)

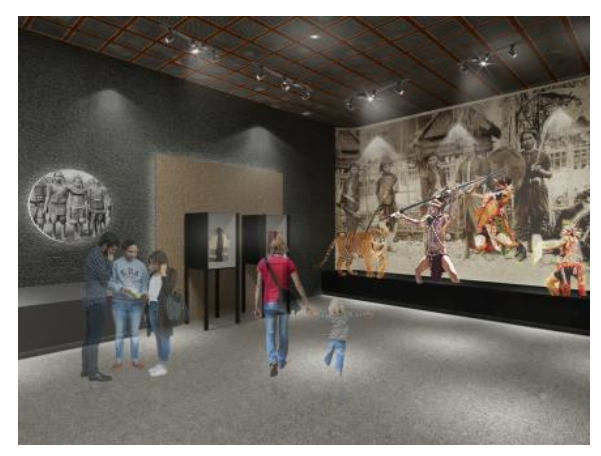

Gambar 25. Pameran Alat Perlindungan (Sumber : Penulis, 2018)

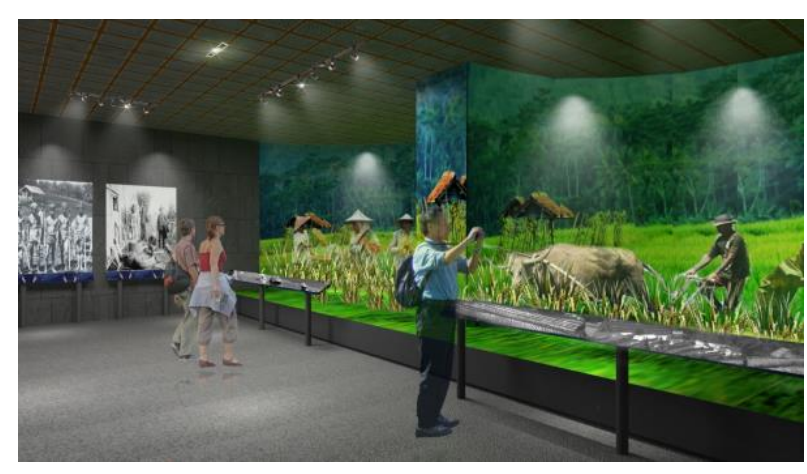

Gambar 28. Pameran Masyarakat Petani (Sumber : Penulis, 2018)

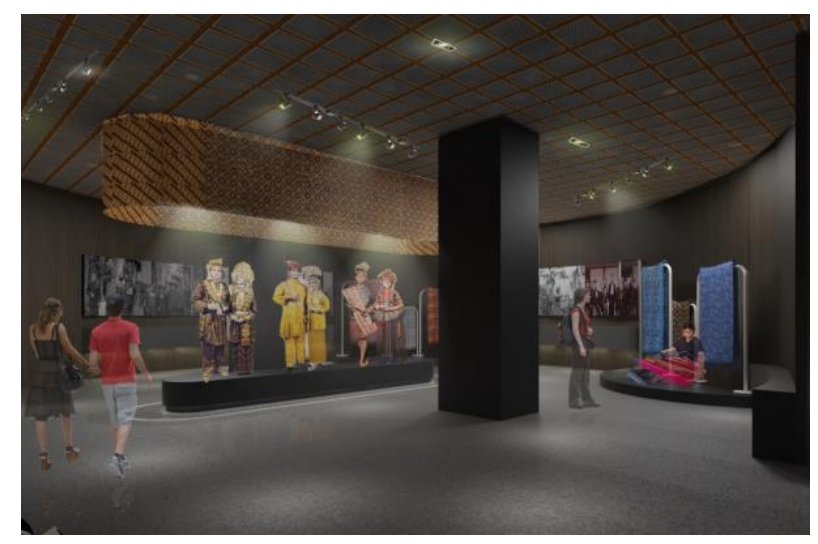

Gambar 26. Pameran Pakaian \& Perhiasan (Sumber : Penulis, 2018)

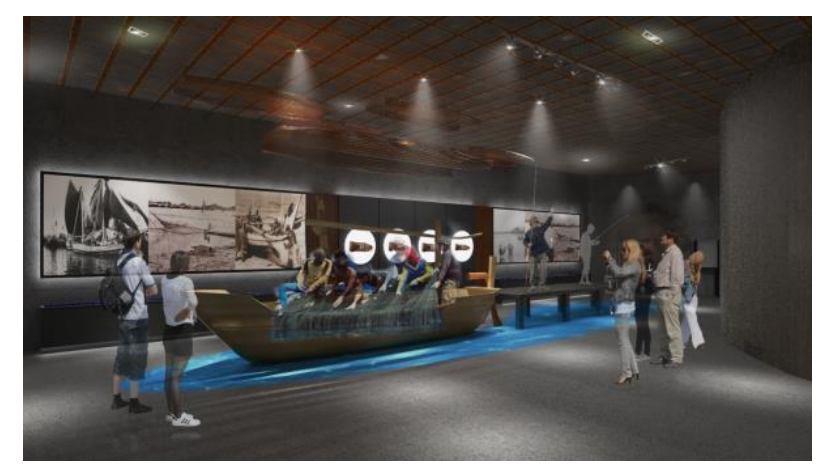

Gambar 27. Pameran Masyarakat Nelayan (Sumber : Penulis, 2018)

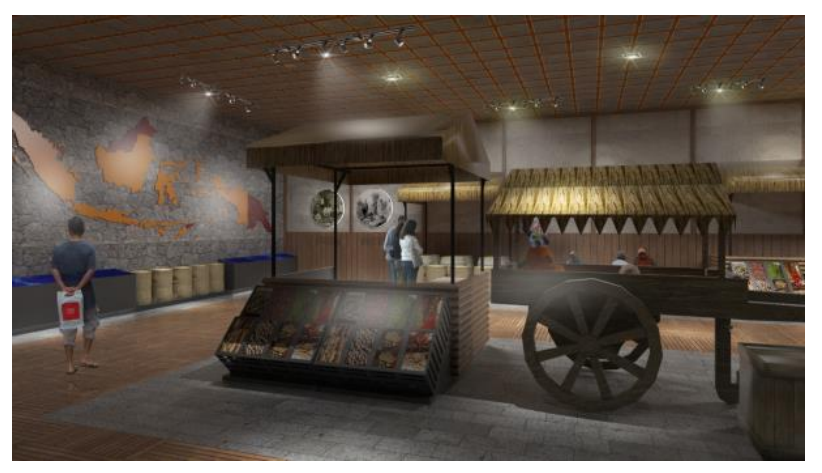

Gambar 29. Pameran Perdagangan

(Sumber : Penulis, 2018) 


\section{UCAPAN TERIMA KASIH}

Ucapan terima kasih ditujukan kepada pengelola Museum Nasional Indonesia yang telah membantu memperoleh data dan informasi yang bermanfaat sehingga perancangan dapat terselesaikan dengan baik.

\section{DAFTAR PUSTAKA}

Boylan, Patrick J. 2004. Running a Museum : A Practical Handbook. France : International Council of Museums

Coleman, Laurence Vail. 1950. Museum

Buildings. Washington, D.C. : American

Association of Museums

Departemen Pendidikan dan Kebudayaan.

1988. Kecil Tapi Indah: Pedoman

Pendirian Museum. Jakarta.

Falk, J.H., and L.D. Dierking, L.D. 2000.

Learning from Museums: Visitor

Experiences and the Making of Meaning.

Walnut Creek, CA: AltaMira Press Hein, George E. 1998. Learning in the Museum. New York : Routledge Wulandari, Anak Agung Ayu. 2014. Dasar-

Dasar Perencanaan Interior Museum.

(Jurnal Humaniora Vol. 5 No.1, BINUS

UNIVERSITY)

Yusiani, Anne Putri. 2010. Pedagogi di Museum. (Tesis). FIB UI. 